\title{
Karakteristikk Klinik Penyakit Saluran Nafas pada Anak
}

\author{
Bob Wahyudin \\ Bagian Ilmu Kesehatan Anak Fakultas Kedokteran Universitas Hasanuddin/ RSU Wahidin Sudirohusodo, \\ Makassar
}

Latar belakang. Angka morbiditas dan mortalitas penyakit saluran napas masih tinggi, terutama pada anak, termasuk di kota Makassar. Rumah Sakit Wahidin sebagai Rumah Sakit Regional Indonesia Timur menerima pasien rawat inap untuk pasien anak dengan penyakit saluran napas, tetapi belum ada laporan tentang karakteristik pasien rawat.

Tujuan. Mengetahui karakteristik klinis pasien rawat di bangsal Respirologi Anak tahun 2010.

Metode. Metode penelitian analitik deskriptif retrospektif dari data sekunder yang disarikan dari status pasien rawat inap.

Hasil. Pada tahun 2010, 264 anak dengan penyakit pernapasan dirawat di bangsal Respirologi Anak RS Wahidin Sudirohusodo, Makassar. Jenis penyakit terbanyak adalah infeksi saluran nafas akut atas (ISPA) 121 (45,83\%) pasien, diikuti pneumonia 106 (40,15\%), tuberkulosis 24 (9,09\%), dan asma $6(2,27 \%)$. Terdapat perbedaan bermakna proporsi gizi buruk, rerata lama rawat dan hitung leukosit saat masuk rumah sakit di antara berbagai jenis penyakit pernafasan. Di antara kasus ISPA atas, tidak terdapat korelasi bermakna antara suhu masuk dan lama rawat, suhu masuk dan hitung leukosit awal, serta antara hitung leukosit dan lama rawat. Pada pasien pneumonia, tidak terdapat perbedaan bermakna antara status gizi dan lama rawat serta antara status gizi dan hitung leukosit. Pada penyakit tuberkulosis, kasus meningitis tuberkulosis memiliki laju pernapasan lebih tinggi dibanding kasus tuberkulosis paru.

Kesimpulan. Penyakit terbanyak adalah ISPA atas, pneumonia, tuberkulosis, dan asma. Umur saat masuk, status gizi, hitung leukosit, dan lama rawat berbeda diantara berbagai penyakit pernapasan. Pasien meningitis tuberkulosis memiliki laju pernapasan yang lebih tinggi dibanding penderita TB paru.

Sari Pediatri 2012;14(1):30-5.

Kata kunci: karakteristik klinik, penyakit saluran napas, rawat inap

\footnotetext{
Alamat korespondensi:

Dr. Bob Wahyudin, Sp.A, IBCLC. Bagian Ilmu Kesehatan Anak Fakultas Kedokteran Universitas Hasanuddin, Jln Perintis Kemerdekaan KM 10, Makassar 90000. Telp. (0411) 588442. E-mail: bob_wahyudin@ yahoo.com
}

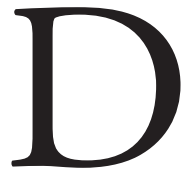
ata Suskernas tahun 2007, mendapatkan $26 \%$ penduduk kota Makassar berada dalam kelompok umur $0-15$ tahun. Sepuluh penyakit utama, ternyata penyakit pernapasan menempati urutan pertama dengan persentase $52,7 \%$ dan menempati urutan 
ketujuh dari 10 penyebab utama kematian di kota Makassar. Pada balita, penyakit pernapasan khususnya pneumonia merupakan penyebab kematian utama, sebesar 22,8\% (Suskernas 2001). ${ }^{1}$

Rumah Sakit Wahidin Sudirohusodo adalah Rumah Sakit Regional tipe A yang berfungsi sebagai rumah sakit rujukan utama di Indonesia Timur, dengan jumlah tempat tidur 673 buah dan Bed Occupancy Ratio $72,60 \%$. Sayangnya belum ada data dan analisis mengenai penyakit-penyakit anak yang dirawat di bangsal anak, apalagi rincian dan analisis pasien yang dirawat dengan kelainan saluran pernapasan.

Tujuan penelitian untuk melaporkan insidens penyakit saluran nafas yang dirawat di Rumah Sakit Wahidin dan analisis hubungan beberapa faktor sosiodemografik, karakteristik klinik penyakit, dan perjalanan penyakit.

\section{Metode}

Data sekunder berasal dari catatan medik pasien yang dirawat di bangsal Respirologi Anak, sejak bulan Januari sampai Desember 2010. Subyek akan dieksklusi bila data tidak lengkap. Dilakukan pengumpulan data pasien antara lain umur, jenis kelamin, pekerjaan orangtua, agama, status gizi, dan status imunisasi. Dilakukan pengumpulan data klinis seperti tanda vital, batuk, ronki, dan hasil pemeriksaan fisik lainnya yang relevan, serta lama sakit. Status gizi dikelompokkan berdasarkan kriteria BB/TB sesuai kurva CDC tahun 2000. Data penyakit tuberkulosis yang dikumpulkan adalah riwayat kontak dan hasil uji tuberkulin. Diagnosis pneumonia ditegakkan secara klinik berdasarkan kriteria WHO, yaitu adanya batuk dan nafas cepat. Rinitis akut, tonsilitis akut, faringitis akut, atau kombinasi keadaan tersebut dikelompokkan sebagai infeksi saluran nafas akut (ISPA) bagian atas. Ditegakkan diagnosis rinitis bila terdapat rinore. Tonsilitis bila ditemukan pembesaran tonsil T3/T3 yang hiperemis. Faringitis bila ditemukan hiperemis pada daerah farings. Pendekatan diagnosis tuberkulosis dilakukan dengan TB Skor dan kemudian dievaluasi lebih lanjut secara klinis dan laboratorik. Pengukuran suhu dilakukan pada aksila dengan menggunakan termometer air raksa.

Analisis statistik menggunakan program SPSS 18. Data yang terkumpul dikelompokkan berdasarkan tujuan dan jenis data, kemudian dilakukan pengujian dengan analisis yang sesuai. Analisis univariat digunakan deskripsi karakteristik data seperti distribusi frekuensi, rerata, dan cakupan. Analisis ini akan menjelaskan karakteristik data seperti sosioekonomi dan geografi. Analisis bivariat menggunakan uji chi square $\left(\mathrm{X}^{2}\right)$, untuk membandingkan proporsi variabel kategorik (status gizi, leukosit). Bila jumlah sampel kurang dari 20 dilakukan uji mutlak Fischer. Uji student-t dan oneway anova digunakan untuk membandingkan nilai rerata dua atau lebih variabel numerik yang mempunyai distribusi dan varians normal (suhu, laju pernapasan). Analisis visual akan dibuat menggunakan scattered plot, histogram atau pie diagram (pengelompokan umur, jumlah pasien perbulan). Kemaknaan uji statistik dinyatakan sebagai bermakna apabila $p \leq 0,05$.

\section{Hasil}

Jumlah pasien yang dirawat di Bangsal Respirologi Anak 278 orang, 14 di antaranya pindah rawat ke Divisi lain karena ternyata tidak menderita penyakit pernafasan, dan 264 dirawat di divisi respirologi dengan berbagai diagnosis penyakit pernapasan. Karakteristik sosiodemografik tertera pada Tabel 1 .

Rerata umur pasien 3,75 tahun dengan umur termuda 8 bulan dan tertua 14,60 tahun, dan paling banyak terdapat pada kelom pok umur satu tahun kebawah. Distribusi status gizi terbanyak mempunyai status gizi baik, diikuti gizi kurang, gizi buruk, dan gizi lebih. Lebih dari separuh pasien telah diimunisasi lengkap $(51,50 \%)$.

Gambar 1 menunjukkan distribusi insidens penyakit pernafasan menurut bulan masuk rawat. Tampak bahwa pasien dirawat terbanyak pada bulan Maret $(\mathrm{n}=38)$ dan paling sedikit pada bulan Juni $(\mathrm{n}=10)$, dengan rerata pasien sebesar 22 pasien/bulan.

Tabel 2 memperlihatkan berbagai diagnosis penyakit pernapasan dan hubungannya dengan beberapa karakteristik klinik. Selama tahun 2010, pasien anak yang masuk ke bangsal respirologi terbagi menjadi 12 jenis menurut diagnosis akhir. Empat jenis penyakit terbanyak adalah ISPA atas 21 $(45,83 \%)$, pneumonia $106(40,14 \%)$, tuberkulosis paru $15(5,68 \%)$, dan asma $6(2,2 \%)$ orang. ISPA atas mencakup sekelompok diagnosis infeksi saluran pernapasan akut bagian atas seperti rinitis, faringitis, tonsilitis atau gabungannya. Diagnosis tumor paru dan kista hidatid dikonfirmasi dengan pemeriksaan $C T$ 
Tabel 1. Karakteristik sosiodemografik dan klinik $(\mathrm{n}=264)$

\begin{tabular}{lllc}
\hline Karakteristik & $\mathrm{n}(\%)$ & Rerata & Rentang \\
\hline Umur (tahun) & & 3,75 & $0,08-14,60$ \\
Laki-laki: perempuan & $138(52,27): 126(47,73)$ & & \\
Gizi & & & \\
$\quad$ Lebih & $5(1,89)$ & & \\
Baik & $192(72,73)$ & & $20-104$ \\
Kurang & $45(17,05)$ & & $80-181$ \\
$\quad$ Buruk & $22(8,33)$ & 46,20 & $35,8-41$ \\
Frekuensi nafas/menit & & 38,3 & \\
Frekuensi nadi/menit & & 14756 & \\
Suhu $\left({ }^{\circ}\right.$ C) & & $2906-72.800$ & \\
Leukosit/mul & & & \\
BB lahir (gram) & & & \\
Status imunisasi & & & \\
$\quad$ Lengkap & $136(51,50)$ & & \\
Tidak/belum lengkap & $58(22,0)$ & & \\
Tidak tahu & $70(26,50)$ & & \\
ASI sampai umur (bulan) & & & \\
0 -6 & $83(31,50)$ & & \\
6-12 & $69(26,10)$ & & \\
$>12$ & $81(30,70)$ & & \\
Tidak pernah & $31(11,70)$ & & \\
\hline
\end{tabular}

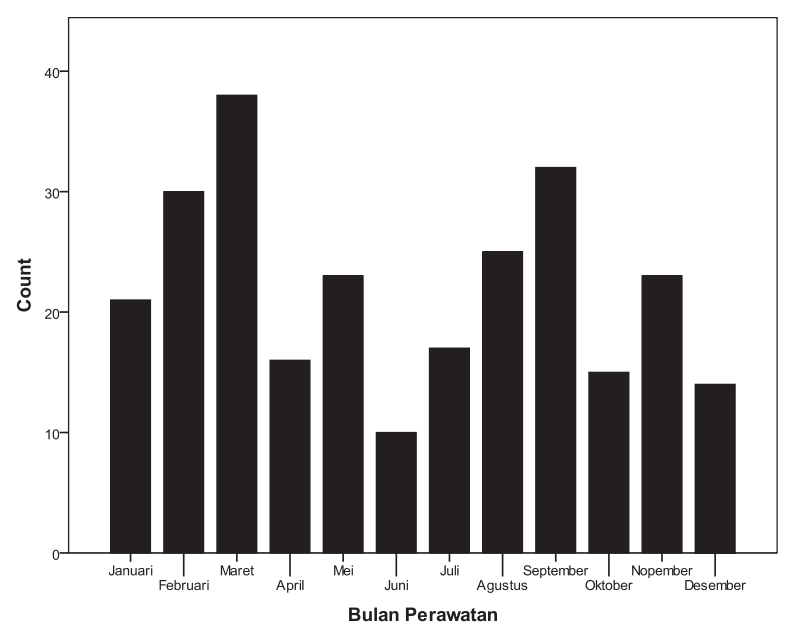

Gambar 1. Insidens penyakit pernapasan menurut bulan

scan. Diagnosis Paraquat lung ditegakkan berdasarkan anamnesis riwayat minum racun rumput golongan paraquat dengan gambaran klinis yang sesuai. Terdapat perbedaan bermakna di antara berbagai diagnosis penyakit saluran pernapasan dengan proporsi gizi buruk $(\mathrm{p}=0,001)$, umur saat masuk $(\mathrm{p}=0,001)$, lama perawatan di rumah sakit $(\mathrm{p}=0,001)$ dan hitung leukosit pada hari pertama rawat $(\mathrm{p}=0,018)$.

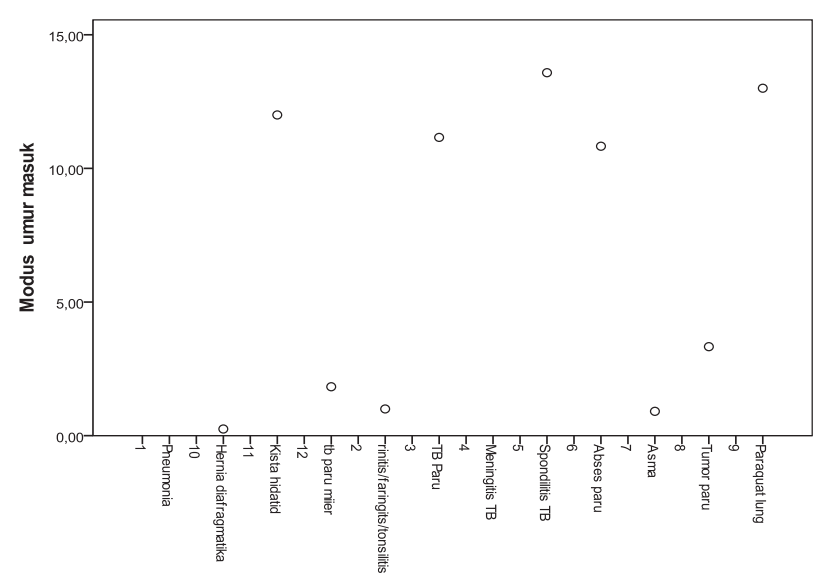

Gambar 2. Modus umur menurut kelompok diagnosis utama

Gambar 2 menunjukkan modus umur pasien dikelompokkan menurut diagnosis utama, terlihat jelas perbedaan modus umur. Anak di bawah lima tahun cenderung menderita ISPA atas, pneumonia dan meningitis TB, sedangkan anak di atas lima tahun sering menderita penyakit tuberkulosis paru dan asma.

Pada pasien ISPA akut, tidak terdapat korelasi antara suhu saat masuk dan lama rawat $(\mathrm{p}=0,19)$, 
Tabel 2. Jenis diagnosis penyakit saluran pernapasan dan hubungannya dengan beberapa karakteristik klinik

\begin{tabular}{lccccc}
\hline Diagnosis & $\mathrm{n}(\%)$ & $\begin{array}{c}\text { Rerata } \\
\text { umur } \\
\text { (tahun) }\end{array}$ & $\begin{array}{c}\text { Gizi } \\
\text { buruk } \\
(\%)\end{array}$ & $\begin{array}{c}\text { Rerata lama rawat } \\
\text { (hari) }\end{array}$ & $\begin{array}{c}\text { Rerata leukosit } \\
\text { (ribu/ } / \text { l) }\end{array}$ \\
\hline Pneumonia & $106(40,15)$ & 1,1 & 13,20 & 8,57 & 15,34 \\
Hernia diafragmatika & $2(0,76)$ & 0,3 & 0 & 16 & 37,31 \\
Kista hidatid & $1(0,38)$ & 12 & 0 & 11 & 6,60 \\
TB paru miier & $1(0,38)$ & 1,8 & 0 & 24 & 14,31 \\
Rinitis/faringits/tonsilitis & $121(45,83)$ & 5,1 & 0,8 & 5,42 & 14,22 \\
TB paru & $15(5,68)$ & 8,4 & 40 & 16,15 & 14,31 \\
Meningitis TB & $6(2,27)$ & 4,1 & 0 & 29 & 13,00 \\
Spondilitis TB & $2(0,76)$ & 13,6 & 0 & 8 & 6,30 \\
Abses paru & $2(0,76)$ & 10,8 & 100 & 15 & 7,00 \\
Asma & $6(2,27)$ & 5,1 & 0 & 2,33 & 14,93 \\
Tumor paru & $1(0,38)$ & 3,3 & 0 & - & 9,50 \\
Paraquat lung & $1(0,38)$ & 13,0 & 0 & 7 & 26,34 \\
Total & $264(100)$ & 3,75 & 8,33 & 7,75 & 14,75 \\
Kemaknaan & & $\mathrm{p}=0,001^{*}$ & $\mathrm{p}=0,001^{*}$ & $\mathrm{p}=0,001^{*}$ & $\mathrm{p}=0,018^{*}$ \\
\hline
\end{tabular}

*Uji Oneway Anova. ${ }^{*} \mathrm{Uji} \mathrm{X}^{2}$

Tabel 3. Karakteristik pasien pneumonia $(\mathrm{n}=106)$

\begin{tabular}{|c|c|c|c|}
\hline Karakteristik & $\mathrm{n}(\%)$ & Rerata & Keterangan \\
\hline Umur (tahun) & & 1,08 & Rentang: $0,08-12$ \\
\hline $0-1$ & $78(73,6)$ & & \\
\hline $1-5$ & $24(22,6)$ & & \\
\hline$>5$ & $4(3,8)$ & & \\
\hline Jenis kelamin & & & \\
\hline Laki-laki & $61(57,54)$ & & \\
\hline Perempuan & $45(42,46)$ & & \\
\hline \multicolumn{4}{|l|}{ Gizi } \\
\hline Lebih & $2(1,9)$ & & \\
\hline Baik & $73(68,9)$ & & \\
\hline Kurang & $17(16)$ & & \\
\hline Buruk & $14(13,2)$ & & \\
\hline Frekuensi nafas ( $\mathrm{x} / \mathrm{menit}$ ) & & 60,48 & $32-104$ \\
\hline Frekuensi nadi ( $\mathrm{x} / \mathrm{menit}$ ) & & 134,34 & $106-181$ \\
\hline Suhu $\left({ }^{\circ} \mathrm{C}\right)$ & & 38,38 & $36,7-41$ \\
\hline Leukosit (ribu/ $\mathrm{\mu l}$ ) & & 15342 & $5600-50.400$ \\
\hline \multicolumn{4}{|l|}{ Status imunisasi } \\
\hline Lengkap & $34(32,1)$ & & \\
\hline Tidak/belum lengkap & $37(34,9)$ & & \\
\hline Tidak tahu & $35(33)$ & & \\
\hline \multicolumn{4}{|l|}{ Pemberian ASI sampai umur (bulan) } \\
\hline $0-6$ & $54(50,9)$ & & \\
\hline $6-12$ & $15(14,2)$ & & \\
\hline$>12$ & $23(12,7)$ & & \\
\hline Tidak pernah & $14(13,25)$ & & \\
\hline
\end{tabular}


Bob Wahyudin: Karakteristik klinik penyakit saluran nafas pada anak

Tabel 4. Karakteristik pasien tuberkulosis

\begin{tabular}{|c|c|c|c|c|c|c|}
\hline Karakteristik & TB paru & $\begin{array}{l}\text { TB paru } \\
\text { milier }\end{array}$ & Meningitis TB & Spondilitis TB & Total & Nilai $\mathrm{p}^{\delta}$ \\
\hline Jumlah kasus & 13 & 1 & 6 & 2 & 22 & \\
\hline Rerata umur (tahun) & 7,93 & 1,83 & 4,12 & 13,58 & 7,12 & $\mathrm{p}=0,10^{*}$ \\
\hline Cakupan & $0,41-14$ & & $0,08-9,75$ & & $(0,08-14)$ & \\
\hline Jenis kelamin, L:P & $6: 7$ & $1: 0$ & $3: 3$ & $1: 1$ & $11: 11$ & \\
\hline Kontak TB dewasa & 7 & 1 & 1 & 1 & 10 & $\mathrm{p}=0,17^{\#}$ \\
\hline Mantoux (mm) & 8,77 & 0 & 11,33 & - & 9,10 & $\mathrm{p}=0,37^{*}$ \\
\hline Cakupan & $0-14$ & & $0-18$ & & $0-18$ & \\
\hline Pernapasan/menit & 38,54 & 72 & 52 & 105 & 121,26 & $\mathrm{p}=0,04^{*}$ \\
\hline Rerata & $(24-72)$ & & $(50-68)$ & $(80-136)$ & $80-160$ & \\
\hline Rerata suhu $\left({ }^{0} \mathrm{C}\right)$ & 38,02 & 38,7 & 38,06 & 37,2 & 37,99 & $\mathrm{p}=0,93^{*}$ \\
\hline Cakupan & $(36,5-40)$ & & $(37-38)$ & $(36,5-37,9)$ & $(36,5-40)$ & \\
\hline Gizi buruk (n) & 6 & 0 & 0 & 0 & 6 & $\mathrm{p}=0,11^{\#}$ \\
\hline Lama rawat (hari) & $\begin{array}{l}14,72 \\
(3-56)\end{array}$ & 24 & $\begin{array}{c}29 \\
(8-47)\end{array}$ & 8 & $\begin{array}{l}17,56 \\
(3-56)\end{array}$ & $\mathrm{p}=0,20^{*}$ \\
\hline
\end{tabular}

${ }^{\delta}$ Hanya dua kelompok yang dibandingkan, kelompok TB paru dan kelompok meningitis TB

*Uji t independen. ${ }^{*}$ Uji mutlak Fischer

suhu dan hitung leukosit saat masuk $(\mathrm{p}=0,93)$, hitung leukosit saat masuk dan lama rawat $(\mathrm{p}=0,95)$.

Tabel 3 memperlihatkan karakteristik kasus pneumonia. Di antara 106 orang pasien, 78 (73,6 $\%)$ berumur kurang dari setahun. Usia termuda 1 bulan dan tertua 12 tahun. Terbanyak pasien adalah laki-laki $(57,54 \%)$ dengan pekerjaan ayah wiraswasta $(36,79 \%)$. Hitung leukosit rata-rata di atas nilai normal. Pada pneumonia tidak ditemukan hubungan antara gizi buruk dan hitung leukosit $(\mathrm{p}=0,522)$ dan tidak ditemukan pula hubungan antara gizi buruk dan lama rawat $(\mathrm{p}=0,72)$.

Tabel 4 memperlihatkan beberapa karakteristik pasien tuberkulosis yang dirawat. Rerata umur pasien 7,93 tahun. Tuberkulosis berat (TB paru milier dan meningitis TB) cenderung terjadi pada usia balita, namun nampaknya perbedaan ini tidak bermakna $(\mathrm{p}=0,10)$. Demikian juga tidak terdapat perbedaan antara kelompok TB paru dan meningitis TB dalam hal kontak TB dewasa $(\mathrm{p}=0,37)$, diameter uji Mantoux $(\mathrm{p}=0,37)$, suhu badan saat masuk $(\mathrm{p}=0,93)$, keadaan gizi $(\mathrm{p}=0,11)$, dan lama rawat $(\mathrm{p}=0,20)$. Satu-satunya perbedaan bermakna adalah pasien meningitis TB mempunyai frekuensi pernafasan lebih cepat dari pada jenis TB yang lain $(\mathrm{p}=0,04)$.

\section{Pembahasan}

Penyakit saluran nafas, termasuk pneumonia dan tuberkulosis tetap menjadi penyebab kematian terbanyak pada anak balita pada negara negara berkembang, meskipun saat ini telah dikembangkan berbagai strategi dan pedoman untuk pencegahan dan tata laksana. ${ }^{2}$ Kejadian global penyakit pneumonia diperkirakan sebesar 0,29 kasus per anak pertahun, berarti kira-kira dijumpai 150 juta kasus baru pertahun. ${ }^{3}$

Di Bagian Anak RS Wahidin Sudirohusodo Makassar, kelompok umur yang paling rawan terkena penyakit saluran nafas adalah kelompok umur di bawah satu tahun. Hal tersebut dapat dimengerti mengingat imunitas selular dan humoral belum berkembang dengan baik. Sejumlah faktor seperti status gizi, umur, status imunisasi, pemberian ASI eksklusif akan mempengaruhi gejala klinik dan outcome. Pada penelitian terdapat perbedaan bermakna pada status gizi, umur, lama rawat, dan hitung leukosit pada berbagai penyakit saluran pernafasan. Pneumonia lebih dipengaruhi umur dan gizi buruk, sedangkan pada meningitis TB, lama rawat lebih panjang dan hitung leukosit relatif lebih tinggi dibandingkan penyakit pernapasan lainnya.

Pada pasien ISPA akut, tidak ditemukan hubungan antara berbagai karakteristik klinik seperti suhu, hitung leukosit, dan lama rawat. Pasien ISPA dirawat di Bagian Anak terutama atas indikasi sosial, atas permintaan orangtua yang merasa khawatir, dan meminta anaknya dirawat karena keluhan demam, sulit menelan, dan badan lemas. Tidak adanya hubungan antara suhu, leukosit, dan lama rawat kemungkinan 
karena anak dengan ISPA rata-rata datang pada awal penyakit dengan gejala relatif ringan. Hal tersebut menyebabkan parameter klinik seperti suhu dan parameter laboratorium seperti jumlah leukosit belum banyak berubah.

Pada pasien pneumonia, beberapa penelitian menunjukkan adanya hubungan antara status gizi dan outcome, ${ }^{4,5}$ tetapi pada penelitian kami tidak terdapat hubungan antara status gizi dengan parameter laboratorium seperti hitung leukosit dan juga tidak mempengaruhi lama rawat. Apakah ini suatu hubungan sebenarnya atau karena jumlah sampel yang belum cukup besar perlu dikaji lebih lanjut. Pada binatang percobaan, malnutrisi dapat menyebabkan fungsi dan ukuran paru berkurang. Penelitian di India dilaporkan fungsi paru anak pada daerah rawan gizi lebih rendah dibanding anak tanpa masalah gizi. Dampak malnutrisi terhadap fungsi paru melalui berbagai mekanisme antara lain menurunkan elastisitas dan fungsi, mengurangi masa otot pernapasan, mempengaruhi sistem imun, mempengaruhi kontrol pernapasan, dan meningkatkan risiko terjadinya edem paru ${ }^{5}$ Pemberian ASI eksklusif sebagai salah satu bentuk asupan nutrisi yang ideal juga mempengaruhi kejadian pneumonia dengan cara yang sama. Insidens pneumonia dapat berkurang sampai !\%-23\% dengan ASI eksklusif. ${ }^{6}$ Pada penelitian kami, pemberian ASI eksklusif hanya 38\%, walaupun dampak terhadap lama rawat tidak berbeda dengan tanpa ASI eksklusif.

Cakupan imunisasi yang lengkap menyebabkan anak tidak mudah menderita pneumonia. Imunisasi yang tidak termasuk dalam Program Pengembangan Imunisasi, misalnya imunisasi Hib dan pneumokokus, juga akan sangat mempengaruhi angka kematian dan kesakitan. ${ }^{6-8}$ Ketiadaan akses terhadap imunisasi Hib dan pneumokokus mungkin dapat menerangkan tidak adanya perbedaan outcome dan gejala klinik pasien pneumonia dengan berbagai status imunisasi.

Gejala klinik seperti suhu badan, nadi, dan pernapasan juga ditemukan tidak berbeda pada pasien pneumonia. Ellis ${ }^{9}$ pada penelitiannya terhadap kasus pneumonia juga tidak memperlihatkan hubungan antara suhu badan, nadi dengan outcome dan angka kematian pneumonia, tetapi menemukan bahwa laju pernapasan merupakan prediktor terhadap buruknya outcome.

Terdapat perbedaan laju pernafasan antara kasus meningitis TB dan TB paru. Laju pernapasan yang lebih cepat pada meningitis TB dapat disebabkan oleh terpengaruhnya pusat napas di medulla oblongata atau juga dapat disebabkan oleh meningkatnya kebutuhan oksigen akibat metabolism yang meningkat. Rerata umur kasus meningitis TB lebih muda, dan sebagaimana diketahui makin muda usia laju pernapasan memang semakin cepat.

Kelemahan penelitian mengandalkan data sekunder dari rekam medik rumah sakit, berpeluang mendapatkan data yang kurang terpercaya. Beberapa data seperti hasil foto toraks dan perjalanan klinis penyakit juga tidak terdata dengan baik. Jumlah kasus tuberkulosis dan asma tidak terlalu banyak, sehingga berpeluang menimbulkan bias dalam analisis. Disarankan di masa depan untuk membuat sistim rekam medik yang lebih baik yang dapat mencatat berbagai aspek perjalanan penyakit beserta hasil radiologik dan laboratorium.

\section{Daftar pustaka}

1. Pemerintah Kota Makassar. Profil kesehatan Kota Makassar Tahun 2007. Makassar: Pemerintah Kota Makassar; 2007.

2. Black RE, Cousens S, Johnson HL. Global, regional and national causes of child mortality in 2008: a systematic analysis. Lancet 2010;375:1969-87.

3. Rudan I, Tomaskovic L, Boschi-Pinto C, Campbell H. Global estimate of the incidence of clinical pneumonia among children under five years of age. Bull World Health Organ 2004;82: 895-903.

4. Abrams, SA. Chronic pulmonary insufficiency in children and its effects on growth and development. J Nutr 2001;131:938S-41S.

5. Laygo RC. Nutritional management pulmonary diseases. Medical Nutrition; December 2007. Didapat dari: http:// xa.yimg.com/kq/groups/20977581/504591245/name/nutr itional+management $+o f+$ pulomonary + disease.pdf

6. WHO. Pneumonia the forgotten killer of children. The United Nations Children's Fund (UNICEF)/World Health Organization (WHO), 2006.

7. Gray D, Zar HJ. Childhood pneumonia in low and middle income countries: burden,prevention and management. Open Infect Dis J 2010; 4:74-84.

8. Juve T, Ruuskanen O, Mertsola J. Symptoms and signs of community-acquired pneumonia in children. Scand J Prim Health Care 2003;21:52-6.

9. Ellis, ME. Factors predicting outcome in patients with pneumonia in Al-Ain, United Arab Emirates. Sausi Med J 2006;27:1044-8. 